\title{
EL TESORO PERDIDO Y LAS REVUELTAS DE LA INDIGNACIÓN: ACTUALIDAD DE LA IDEA ARENDTIANA DE REVOLUCIÓN
}

\author{
The lost treasure and the rebellions of the indignant: actuality of Hannah Arendt's idea \\ of revolution.
}

Jordi Carmona Hurtado

UFCG

\begin{abstract}
Resumen: Este trabajo parte de una suposición simple: que existe una afinidad profunda entre lo que podemos llamar de un modo aproximativo los movimientos o revueltas de la indignación (desde Túnez y Egipto hasta España y EEUU o Turquía y Brasil) y los análisis arendtianos del fenómeno revolucionario, en especial en lo que respecta al "tesoro perdido" de las revoluciones: sociétés populaires, distritos y secciones comunales, Soviets o Räte. Estas formas de poder colectivo han sido según Arendt las únicas que han mostrado ser capaces de dar un espacio perdurable al espíritu de la Revolución - "un espíritu nuevo, y el espíritu de dar origen a algo nuevo" -, pero han sido no sólo derrotadas por todas partes sino también malentendidas y olvidadas. Nuestro propósito a este respecto es mostrar, aparte de las razones de esta afinidad, que la perplejidad política que los movimientos recientes han generado no se diferencia de la que no ha dejado de provocar este "tesoro perdido".
\end{abstract}

Palabras clave: Hannah Arendt, tesoro perdido, tradición revolucionaria, movimientos de indignación.

\begin{abstract}
In this work we argue that there is a profound familiarity between what we call the movements and the rebellions of the indignant (from Tunis and Egypt to Spain and EEUU or Turky and Brazil) in one side, and the Arendt's analysis on the revolution in the other side; specially considering the "lost treasure" from the revolutions: sociétés populaires, districts and comunal sections, Soviets or Räte. This formations of popular power had been, as Arendt said, the single ones that showed a real capacity to give an abiding space to the revolutionary spirit - "a new spirit, and the spirit of beginning something new"-, but they where not only defeated everywhere but also misunderstood and forgotten. Our purpose here is to argument, besides the reasons of this familiarity, that the political perplexity induced by the actual movements is not radically different from the other perplexity which the "lost treasure" keeps inducing from its first appearance.
\end{abstract}

Keywords: Hannah Arendt, lost treasure, revolutionary tradition, indignation movements. 


\section{Introducción: denken ohne Gëlander y arqueología de la revolución}

A menudo se ha señalado la independencia de espíritu de Arendt como un rasgo siempre notable en sus reflexiones; ella misma ha dado algunos elementos para una teoría de esta independencia, principalmente con la idea del "Denken ohne Gëlander", del "pensar sin barandillas"1 al que nuestra situación histórico-filosófica nos obligaría si queremos revelar algo del mundo que compartimos, una vez que vivimos en los tiempos entre un "ya no" y un "no todavía", que nos encontramos a la intemperie, en un presente que no es sino un hiato, una brecha entre un pasado olvidado y un futuro inimaginable. De esta situación crítica, en la que se sitúan y a partir de la cual se desarrollan el conjunto de meditaciones de Arendt, como una manera de habitar el hiato mediante el pensamiento, las revoluciones dan un doble testimonio. Por un lado, en su análisis del fenómeno revolucionario, Arendt no deja de señalar la discrepancia entre lo inaudito de los acontecimientos y acciones en curso, e incluso la audacia de los revolucionarios al considerarlos y enfrentarse a ellas, y lo caduco de las categorías de pensamiento con las que los subsumían, de los esquemas y hábitos intelectuales con los que daban cuenta de ellas: el hiato, por tanto, es aquí el abismo entre el pensamiento, el pensamiento heredado de la tradición occidental, y la acción, la acción inédita de la revolución. Pero por otro lado, si la revolución ha sido portadora de una promesa que toca de muy cerca a la filosofía, es precisamente ésta: que se salve por fin el abismo entre el pensamiento y la acción; y en fin que la filosofía, que según Arendt, desde el fin de la época de Pericles se ha divorciado del mundo compartido, vuelva a él².

Como puede observarse por estas consideraciones preliminares, el fenómeno de la Revolución se sitúa en el centro de las inquietudes filosóficas de Arendt: el análisis del fenómeno revolucionario en On Revolution es un terreno privilegiado para

1 Ver las declaraciones de Arendt en un debate que tuvo lugar en 1972: ARENDT, Hannah. "Arendt sobre Arendt. Un debate sobre su pensamiento", in De la historia a la acción, traducción de Fina Birulés. Barcelona: Paidós, 1972, p. 170.

${ }^{2}$ ARENDT, Hannah. Sobre la revolución, trad. Pedro Bravo. Madrid: Alianza, 1988, p. 243 
el Denken öhne Gëlander. Pero de un modo más directo, la célebre independencia de espíritu de Arendt hace que su interpretación de la revolución vaya a contracorriente de toda una serie de interpretaciones habituales, y haya suscitado un buen número de perplejidades. Así, el historiador Eric Hobsbawm encontrará en suma en este estudio más oscurecimientos que iluminaciones ${ }^{3}$. Pero fundamentalmente, y este es el primer punto en que podemos decir que la actitud de Arendt simpatiza con el espíritu de indignación, su interpretación cuestiona lo que podemos llamar el monopolio de izquierdas de la tradición revolucionaria.

Esto no quiere decir que Arendt inaugure la apropiación revisionista, neoconservadora o simplemente "de derechas" de la revolución. Tampoco conforta en absoluto a los que consideran que la única revolución posible es la revolución liberal o burguesa. Es necesario restituir el movimiento polémico del estudio de Arendt, que en efecto a menudo se deja resumir en oposiciones demasiado abstractas, a su complicación y a su diferenciación. Podemos describir la orientación general de la obra según un movimiento que desde un presente extremadamente sedimentado, va eliminando capas superpuestas de conceptos y esquemas, hasta encontrar elementos de decisión, que marcaron el devenir de esos conceptos y esquemas; desde esos elementos de decisión, se dirige hacia los fenómenos que los originaron; tras esos fenómenos originarios, que han marcado el devenir del mundo y la preponderancia fáctica de una forma de la revolución, encuentra un origen todavía más oculto, el verdadero origen, pero para mostrar que este origen, el verdadero comienzo de nuestro tiempo, no ha originado nada en la realidad, ha permanecido impotente aunque fuese el único realmente capaz de originar el mundo nuevo, ha sido casi siempre mal entendido incluso por aquellos que lo vieron nacer, y en consecuencia enterrado, olvidado, anulado. Así, en un sentido propio de la expresión, que no es, por ejemplo, el de Foucault ${ }^{4}$, vemos que la obra de Arendt es una arqueología de la

3 Cf: HOBSBAWM, E. J. “Hannah Arendt on Revolution”, in Revolutionaries. London: New Press, 1973.

4 Foucault utilizará el término de arqueología no en el sentido de la lógica de los orígenes o de la investigación de los comienzos, sino en un sentido indirecto, más humorístico: se trata del estudio de los 
revolución y de la tradición revolucionaria. Si dotamos de contenido al movimiento que acabamos de indicar, la obra de Arendt parte del presente de los esquemas y conceptos marxistas, como única teoría válida y consagrada de la revolución, y como verdadera fijación intelectual de los revolucionarios de los años sesenta en que escribe su libro, frecuentemente mantenida ante fenómenos que no dejan de invalidarla; se dirige luego a los elementos originarios de esta teoría, fundamentalmente la preponderancia de la cuestión social, en la secuencia de acontecimientos de la Revolución Francesa, repetidos durante la Revolución de Octubre; tras ello escarba un poco más hasta el origen del deseo de Revolución en Francia y de la aparición de esa cuestión social: la Revolución Americana y la situación de abundancia económica en esa región del mundo; finalmente, se retrotrae a las experiencias de la colonización, al análisis del sentido del pacto del Mayflower como origen del origen, y a la irrupción discontinua de este origen del origen en las sociétés populaires francesas, en los sóviets rusos, en los consejos alemanes y húngaros.

Así, la tesis de Arendt en este libro no consiste en absoluto en decir que la verdadera revolución es la americana, y no la francesa. Su arqueología de la revolución y de la tradición revolucionaria no ofrece este resultado, pues, según sus propias palabras, "el espíritu de la revolución [...] no logró encontrar su institución adecuada" 5. El verdadero resultado de su estudio es que la historia de las revoluciones, que según Arendt es la historia más íntima de nuestro tiempo, la que nos dice realmente quiénes somos $^{6}$, consiste en la aparición discontinua de un "tesoro" que no ha logrado fundarse; y que si bien podemos decir que nuestro tiempo viene de la revolución, no vivimos en absoluto en el mundo de la revolución: esta herencia no encontró testamento, según la célebre fórmula de René Char a menudo invocada por Arendt. En consecuencia, nuestra experiencia permanece sin origen; lo que es idéntico según Arendt a decir que en nuestras vidas no experimentamos sino muy raramente la

archivos. Ver, por ejemplo: FOUCAULT, Michel. "Michel Foucault explique son dernier livre", in Dits et écrits. Vol. I 1954-1969. Paris: Gallimard, 1994, p. 772.

5 ARENDT, Hannah. Sobre la rev., p. 387.

6 Cf. el prefacio de: ARENDT, Hannah, Between past and future. New York: Viking Press, 1961, p. 5. 
libertad, en el sentido plenamente político de la palabra, como capacidad de comenzar: el initium que es el otro nombre del hombre ${ }^{7}$.

\section{Revolución social}

Si estos breves enunciados pueden resumir lo que podemos llamar el sentido más positivo del libro, su alcance más profundo y su capacidad de cuestionar toda una tradición que a menudo paraliza más que favorece la emancipación de los sujetos, la insistencia de Arendt en este sentido positivo de la revolución - fundar un espacio de libertad - no puede hacernos olvidar la parte más débil y limitada de su estudio, que es la concerniente a la cuestión social. Pues en general, salvo precisamente en el análisis de las experiencias consejistas, el papel de los pobres, de los trabajadores en On Revolution es el de expresar deseos violentos, que perturban la buena marcha de las revoluciones, transformando el deseo de fundar la libertad en el deseo de conseguir pan para todos ${ }^{8}$. En ciertas declaraciones, Arendt afirmó que lo que más interrogantes le suscitó en la empresa revolucionaria fue el modo en que los revolucionarios, con la voluntad de entender lo inaudito de los procesos en curso, se volvieron hacia ciertos textos antiguos ${ }^{9}$. Y desde un punto de vista metodológico, es sin duda muy significativo el modo en que Arendt se interesa por todo lo que pudieron decir y escribir los actores de la revolución; su interés por todo lo que el marxismo Ilama la superestructura ilusoria, en detrimento de la infraestructura real. Pero incluso fuera de los postulados de historiadores más o menos marxistas como Hobsbawm, podemos lamentar que en lo que toca a la cuestión social, o por decirlo más propiamente, a la revolución social, Arendt no haya sentido ninguna curiosidad por investigar qué pudieron escribir y decir los actores de esta revolución social, en vez de enunciar ese tipo de juicios casi automáticos que contradicen, por otra parte, su propria teoría del juicio político. Aunque esto tampoco se le puede reprochar

\footnotetext{
7 Cf. ARENDT, Hannah. Sobre la rev., p. 291.

8 Cf. los capítulos "La cuestión social" y "La búsqueda de la felicidad" en: ARENDT, Hannah. Sobre la rev.

${ }^{9}$ Cf. ARENDT, Hannah. Sobre la rev., p. 162.
} 
demasiado; pues ni siquiera los intelectuales marxistas se interesaron significativamente por el pensamiento o la palabra obrera, y ha habido que esperar a que se efectuara un trabajo de crítica interna dentro del marxismo para que se produjeran obras que han acogido este pensamiento y palabra obrera, como La formación de la clase obrera en Inglaterra de E. P. Thompson (1963), publicado el mismo año que el libro de Arendt, o tentativas más sui generis como La noche de los proletarios de Rancière (1981). En cualquier caso, el hecho de que el movimiento obrero no sea ni nombrado en un análisis del fenómeno revolucionario de los últimos dos siglos constituye una laguna y una limitación real del estudio de Arendt. Aunque, una vez más, al menos en parte, este vacío es subsanado anticipadamente por el apartado dedicado al movimiento obrero en el capítulo sobre la acción de La condición humana. Pero no deja de ser enigmático que la misma autora que en esa obra lo define como uno de los movimientos revolucionarios más importantes de nuestro tiempo ni siquiera lo nombre en el libro dedicado explícitamente a la Revolución.

Quede señalado este enigma y fijado del modo siguiente el límite mayor del estudio de Arendt: la revolución social no figura en él; sólo figura una cuestión social que es precisamente una cuestión o problema para la revolución política, que es la única que considera Arendt. Pero este límite no significa que On Revolution sería la obra de una pensadora aristocrática de la política, como por ejemplo Habermas le ha reprochado ${ }^{10}$. Baste un ejemplo a este respecto, que muestra que la libertad política no se opone, sino que más bien puede ser la condición, en la modernidad, de una hegemonía popular en la sociedad. Cuando analiza documentos de la Comuna de París de 1871, otro ejemplo para ella del "tesoro perdido" de la revolución, se detiene en uno que precisamente une la fundación de la libertad política a la mayor transformación social. Se trata de las palabras del publicista de la Comuna Odysse Barot:

\footnotetext{
${ }^{10}$ Cf.: HABERMAS, J., "Hannah Arendt's communication concept of power". In: Social Research. New
} York: v. 44, n. 1, 1977. 
En tanto que revolución social, 1871 procede directamente de 1793, que continúa y debe acabar... En tanto que revolución política, al contrario, 1871 es una reacción contra 1793 y un retorno a $1789 . .$. Ha borrado del programa las palabras "una e indivisible" y rechazado la idea autoritaria que es una idea monárquica... para unirse a la idea federativa, que es por excelencia la idea liberal y republicana. ${ }^{11}$

\section{Libertad y contractualismo revolucionario}

Ahora bien, es importante no confundirse con el contenido de esta "idea liberal y republicana" que Arendt subraya. "Liberal", aquí, es un calificativo político, y no nombra ni una doctrina económica que reconocería una autonomía del mercado a la hora de fijar los precios de las mercancías ni un modo de gobierno que garantizaría esta autonomía o se vería limitado por ella. "Liberal" tampoco nombra un modo de gobierno que respetaría o garantizaría la independencia de los ciudadanos y algunos derechos básicos: información, reunión, manifestación, etc. ${ }^{12}$ Este conjunto de rasgos de lo que entendemos habitualmente por liberalismo, para Arendt configuran lo que ella llama más bien en el ensayo un "gobierno limitado", y que es un tipo de gobierno que existe al menos desde el siglo XVII en Inglaterra, desde Cromwell ${ }^{13}$.

Pero lo fundamental según Arendt de la ruptura revolucionaria, y este es el punto en donde reside la mayor radicalidad de su ensayo, es que las revoluciones no se han hecho simplemente para limitar la autoridad o la soberanía, para facilitar la emergencia y la independencia de esa instancia no política que llamamos la sociedad civil. Como la misma Arendt dice, "o la libertad, políticamente hablando, significa el derecho a ser co-partícipe en el gobierno, o no significa nada"14. El carácter, a nuestro

\footnotetext{
${ }^{11}$ ARENDT, Hannah. Sobre la rev., p. 368. Arendt cita en el francés original, nosotros traducimos. Las cursivas también son de Arendt.

${ }^{12}$ Sobre el liberalismo considerado al mismo tiempo como dispositivo económico y arte de gobierno, los cursos de Foucault Sécurité, territoire, population (1977-1978) y Naissance de la biopolitique (19781979) constituyen una referencia esencial.

${ }^{13}$ Cf.: ARENDT, Hannah. Sobre la rev., p. 198.

${ }^{14}$ ARENDT, Hannah. Sobre la rev., p. 300.
} 
juicio, precioso de su ensayo, consiste en recordar y hacer ver en cierto modo el mundo sensible de esta libertad política, que hoy aparece en general olvidada por todos, también por la izquierda. Así, que el enfoque de Arendt en su ensayo sea principalmente político, no da como resultado que menosprecie las preocupaciones sociales populares, sino que siempre mantiene a la vista este tesoro de la revolución. Es el tesoro de la libertad entre iguales: de la vida activa para cada uno, de la capacidad de hablar y actuar en un mundo público, y así ser partícipe en el destino colectivo. No hay otro significado de la revolución: esta consiste en la abolición de la soberanía, como instancia separada de gobierno, en el fin de la diferencia entre gobernantes y gobernados, en el despliegue de una vida política que se regiría por el axioma "ni mandar ni obedecer"15, que ella retoma de Heródoto. Cuando los revolucionarios hablaban de la fundación de la libertad no querían decir otra cosa que esto, según Arendt. Esta es, por otra parte, la empresa de (fundación de la) libertad que Arendt, en ciertos lugares de su ensayo, diferencia de la empresa de liberación (de la opresión). Y que nos permite decir que, en esta perspectiva, si bien en cierto modo estamos liberados, pues existe una cierta independencia civil, no somos en absoluto libres, pues en nuestra sociedad apenas es posible actuar en el sentido de Arendt. Nuestra libertad es privada, no pública; podemos elegir quién nos gobierna, no gobernar: se trata de la libertad del esclavo.

La experiencia de este tipo de libertad pública es, a grandes rasgos, el tesoro de la revolución. Según Arendt, la forma de existencia de este tesoro coincide con la de los consejos, la democracia directa de las asambleas populares. Y en efecto, a lo largo de su ensayo, Arendt trata de mostrar que los consejos, en sus diferentes variedades, han constituido la forma verdaderamente nueva de gobierno que la revolución ha gestado. Sin embargo, y esto incluye a la Revolución americana por mucho que

\footnotetext{
${ }^{15}$ La expresión en griego es "oute gar arkhein aoute arkhestai ethelô" (ARENDT, Hannah. Sobre la rev., p. 38), ni mandar ni ser mandado, y es pronunciada en Heródoto por Otanés, el defensor persa de la democracia (isonomia), que resume así su sentido.
} 
Jefferson insistiera al final de su vida ${ }^{16}$, esta forma de gobierno nunca ha sido fundada o instituida. Lo que se ha impuesto en todas partes es el sistema de partidos, que es una herencia del Antiguo Régimen, que simplemente restringió la soberanía mediante el sistema de gobierno limitado. Como Arendt señala igualmente, la alternativa real, sin conciliación posible, en el tiempo de las revoluciones, ha sido la alternativa entre sistema de partidos y sistema de $\operatorname{consejos}^{17}$. El sistema parlamentario de partidos está sometido, como analiza Arendt, a la aporía de la representación: o bien los representantes del pueblo tienen autonomía de decisión, y por tanto se reproduce la división entre gobernantes y gobernados, y el gobierno del pueblo es una farsa; o bien son mandatarios directos de los electores, y entonces la vida política se pierde en la pura administración de los intereses ${ }^{18}$. Entre el monopolio y el clientelismo circularía según Arendt la vida pública de nuestras sociedades. Pero el sistema de consejos, el único capaz de posibilitar una vida política efectiva al gran número, no ha llegado por tanto a ser fundado.

De ahí la operación crítica de Arendt, frente a la tradición revolucionaria. Pues en el ensayo no sólo trata de acabar con el monopolio de izquierdas del sentido de la revolución. También trata más generalmente de desolidarizar el espíritu de la revolución del espíritu de partido, incluso (presuntamente) revolucionario. Como muestra Arendt, los partidos revolucionarios acabaron con el consejismo allí donde alcanzaron el poder, tanto en Francia como en Rusia, acabando así igualmente con ese mundo de la igualdad política donde no hay lugar a diferenciar entre gobernantes y gobernados ${ }^{19}$.

Pero también de ahí su operación más positiva, que consiste en interrogar de qué modo podría fundarse el consejismo. Aquí es preciso nombrar una de las contribuciones al pensamiento político más importantes del libro: se trata de lo que podemos llamar la teoría del contractualismo revolucionario, oponiéndolo así al

\footnotetext{
${ }^{16}$ Cf.: ARENDT, Hannah. Sobre la rev., p. 351.

${ }^{17}$ Cf.: ARENDT, Hannah. Sobre la rev., p. 372.

${ }^{18}$ Cf.: ARENDT, Hannah. Sobre la rev., p. 372.

${ }^{19} \mathrm{Cf}$. : ARENDT, Hannah. Sobre la rev., pp. 345-356.
} 
clásico, de Hobbes, Rousseau o Locke. Esta teoría del contractualismo revolucionario, sin embargo, Arendt la extrae de la experiencia precisa del descubrimiento, según ella, del sentido más original de la política durante la liberación de los colonos norteamericanos del mando de la monarquía inglesa. Se trata de lo que hemos llamado más arriba el origen del origen de esta historia de la Revolución: es lo que Arendt llama "el Acontecimiento", el acontecimiento con mayúsculas, que sin embargo, como hemos visto, no ha sido ni reconocido como tal ni por tanto fundado en ninguna Revolución. El origen de la Revolución, no lo que hicieron las revoluciones mismas, es cierto modo inédito de asociación entre los hombres que Arendt detecta en el momento del Pacto del Mayflower, a partir del cual ella define eso que podemos llamar una teoría del contractualismo revolucionario.

Con la oposición de este tipo de contractualismo al clásico podemos acabar de entender en qué se opone según Arendt el tipo de sociedad que hizo aparecer la Revolución, para perderla sin embargo a continuación, al Antiguo Régimen o a su reforma en la sociedad de gobierno limitado. Fundar el "tesoro perdido" significa lo siguiente, por oposición al viejo tipo de contrato:

El contrato muto mediante el cual los individuos se vinculan a fin de formar una comunidad se basa en la reciprocidad y presupone la igualdad; su contenido real es una promesa y su resultado es ciertamente una "sociedad" o "coasociación", en el antiguo sentido romano de societas, que quiere decir alianza. Tal alianza acumula la fuerza separada de los participantes y los vincula en una nueva estructura de poder en virtud de "promesas libres y sinceras". De otro lado, en el llamado contrato social suscrito entre una determinada sociedad y su gobernante, estamos ante un acto ficticio y originario de cada miembro, en virtud del cual entrega su fuerza y poder aislados para constituir un gobierno; lejos de obtener un nuevo poder, mayor eventualmente del que ya poseía, cede su poder real y, lejos de vincularse mediante promesas, se limita a manifestar su "consentimiento" a ser gobernado por el gobierno [...] Por lo que se refiere al individuo, es evidente que gana tanto poder con el sistema de promesas mutuas como pierde cuando presta su consentimiento a que el poder sea monopolizado por el gobernante. A la inversa, aquellos que "pactan y se reúnen" pierden, en virtud de la reciprocidad, su aislamiento, mientras en el 
otro caso es precisamente su aislamiento el que es garantizado y protegido. ${ }^{20}$

Hemos hablado de teoría del contractualismo revolucionario, pero lo que los colonos descubrieron son las "pocas verdades fundamentales sobre las cuales se levanta la teoría del contrato"21. Pero lo esencial de estas pocas verdades fundamentales es que invierten completamente el contractualismo clásico. Si en él la esfera política aparece siempre como una esfera de dominación, a la que los individuos, que sólo son libres en el estado de naturaleza, ceden una parte de su poder, lo que el contractualismo revolucionario descubre es que sólo mediante la promesa mutua, mediante el pacto y la asociación es posible disponer de algún poder. El poder viene de la relación, y hay un sentido positivo de la sociedad política, un sentido de igualdad y reciprocidad que nunca se podrá experimentar estando aislados.

Este acontecimiento, este origen del origen del fenómeno revolucionario, es tan fundamental, podemos decir con Arendt, que incluso es imposible, por volver una vez más a la revolución social, entender la utopía comunista, en su sentido más persistente -es decir, en el sentido de la libre asociación de los trabajadores-, sin él. Así, el requisito principal de una fundación posible de los consejos, de una fundación del "tesoro perdido", consistiría en retomar contacto con el sentido más íntimo de esta forma del contractualismo revolucionario.

Pero este sentido no consiste simplemente en la abolición de la soberanía, y por tanto del Estado. Cada vez que pensamos así el sentido de la política, o de la revolución, nos situamos en el marco clásico del contractualismo; o confundimos, como diría Arendt, liberación y libertad. Lo esencial, y lo más difícil, según parece, para los movimientos actuales, es entender el vínculo positivo entre libertad y poder que resulta del pacto y la promesa mutua que permiten actuar juntos a los hombres.

${ }^{20}$ ARENDT, Hannah. Sobre la rev., p. 232-233.
${ }^{21}$ ARENDT, Hannah. Sobre la rev., p. 238. 
Conclusión: El tesoro perdido y los movimientos de indignación

Pues en efecto, puede decirse que la importancia de los movimientos populares recientes, surgidos a partir de las revoluciones árabes, y tomados en su conjunto, consiste principalmente en que han permitido a multitud de individuos experimentar qué significa vivir políticamente de este modo elemental de la expresión al que se refiere Arendt: les ha permitido dejar por un momento de estar aislados, y experimentar un poder y una libertad que provienen del hecho de actuar juntos, de ligarse mediante mutuas promesas aunque sea durante el tiempo de una acción o de una serie de acciones. Un espacio de apariencias y de libertad, en el sentido en que habla Arendt en diferentes lugares de su obra, ha empezado a existir desde que multitudes de individuos tomaron las calles y plazas públicas de diferentes países, y allí trataron de permanecer y organizarse para actuar juntos.

Los resultados de estos procesos diversos, pero que tienen en común este modo de volver a tomar contacto con la política en el sentido positivo y revolucionario de la palabra, son también diversos. Según parece, por ahora, en Túnez, allí donde todo empezó, el proceso ha dado lugar a la implantación de un discreto gobierno limitado. En Egipto, como se sabe, la revolución aún no ha acabado, y puede tomar caminos imprevisibles, también el de la guerra civil. La revuelta llamada de indignación en España, y los movimientos que a su ejemplo tuvieron lugar en EEUU principalmente pero también en otros países, así como en cierto modo más recientemente, en Turquía o Brasil, han sido en general menos eficaces; pero esto es comprensible habiendo tenido lugar en países regidos en mayor o menos medida por gobiernos de tipo limitado; y en tanto no se considere seriamente que el objetivo de la revolución no es ese, parece difícil que la situación vaya a ir más lejos.

Sin embargo diferentes rasgos de estos movimientos han conectado con lo que según Arendt es la forma más auténtica de la tradición revolucionaria. Podemos nombrar varios: su carácter apartidista, que tan sospechoso ha parecido tanto como para la izquierda como para el "sistema" en general; su estructura igualitaria y 
horizontal; su organización en asambleas populares, que en Madrid por ejemplo dio lugar también a una federación de asambleas de barrio; su inclusividad, que les ha ocasionado críticas constantes por carecer de ideología, como si esto supusiera una falta de radicalidad, cuando hoy todas las ideologías concuerdan en decir que en el fondo no hay ninguna alternativa al sistema.

Estas experiencias han vuelto a traer a la superficie del mundo, y a los ojos de muchos, lo esencial del fenómeno revolucionario: y eso es un hecho real e imborrable para todos los que han participado en ellos. Lo que no quiere decir que esté claro cómo pasar del gobierno limitado a una verdadera fundación de ese espacio de libertad. Por ahora sólo podemos decir que la lectura del ensayo de Arendt podrá dar a los revolucionarios confianza sobre lo bien fundado de sus intuiciones básicas, y dar mayor consistencia a una práctica de la política que ha sido atacada tan ferozmente, cuando no simplemente malentendida y anulada.

\section{Referências}

ARENDT, Hannah (1958). The human condition. Chicago: University of Chicago Press.

- (1961). Between past and future. New York: Viking Press.

- (1963). Sobre la revolución, trad. Pedro Bravo. Madrid: Alianza, 1988.

- (1972). "Arendt sobre Arendt. Un debate sobre su pensamiento". De la historia a la acción, trad. Fina Birulés. Barcelona: Paidós, 1995.

FOUCAULT, Michel (1994). "Michel Foucault explique son dernier livre", Dits et écrits. Vol. I, 1954-1969. Paris: Gallimard.

- (2004). Sécurité, territoire, population. Cours au Collège de France (1977-1978). Paris: Gallimard/Seuil.

- (2004). Naissance de la biopolitique. Cours au collège de France (1978-1979). Paris: Gallimard/Seuil.

HABERMAS, Jürgen (1977). "Hanna Arendt's communication concept of power". In: Social Research. New York: v. 44, n. 1. 
HOBSBAWM, E. J. (1973). "Hannah Arendt on Revolution", Revolutionaries. London: New Press.

RANCIÈRE, Jacques (1981). La nuit des prolétaires. Archives du rêve ouvrier. Paris: Fayard/Hachette.

THOMPSON, E. P. (1963). La formación de la clase obrera en Inglaterra. Madrid:

Capitán Swing, 2012.

Doutor em Filosofia pela Université de Paris 8 e pela Universidad Autónoma de Madrid E-mail: zoparo@gmail.com 